\title{
A RELEVÂNCIA DAS ATIVIDADES PRESENCIAIS PROMOVIDAS PELOS POLOS EAD, NA VISÃO DOS ALUNOS
}

\author{
SÃO PAULO/SP JUNHO/2018
}

\author{
Lidiane Moutinho Neves - Unicid - lidiane.moutinho@gmail.com \\ Celia Maria Haas - Unicid - celiahaas1@gmail.com \\ Maria Cristina Mendonça Siqueira - Unicid - cristinamendonca.sp@gmail.com \\ Carlos Augusto Baptista de Andrade - Cruzeiro do Sul - 21carlos.andrade@gmail.com \\ Egídio de Oliveira Filho - Cruzeiro do Sul - egidio22_oliveira@yahoo.com.br \\ Carlos Fernando de Araújo Jr. －Cruzeiro do Sul - cfaraujojr@gmail.com
}

Tipo: Investigação Científica (IC)

\author{
Natureza: Descrição de Projeto em Andamento \\ Categoria: Pesquisa e Avaliação
}

Setor Educacional: EDUCAÇÃO SUPERIOR

\begin{abstract}
RESUMO
Atualmente, os polos EAD podem ser considerados, na estrutura da modalidade, um dos responsáveis pelo crescimento exponencial da Educação a Distância registrado no Brasil nos últimos anos por viabilizar aos cidadãos das localidades mais distantes do país, acesso à Educação Superior. O polo deve atuar como um prolongamento da Instituição de Ensino Superior que representa pois, além de prestar atendimento administrativo, facilita a adaptação dos discentes à metodologia EaD, viabilizando o desenvolvimento de atividades presenciais e contribuindo no processo de ensino e aprendizagem, à medida que possibilita ações que estão previstas nos Projetos Pedagógicos dos Cursos (PPCs). O presente artigo analisa a relevância das atividades presenciais, na visão dos alunos, a partir das respostas registradas para esse tema, no relatório de Avaliação Institucional Interna aplicado pela Comissão Própria de Avaliação (CPA), de uma Universidade Particular. O questionário aplicado em 2016 para 13.891 alunos matriculados em cursos de graduação, em 05 polos-sede distintos, obteve 6.531 respondentes. O estudo investigativo se concentrou na Aula Inaugural, atividade acadêmica desenvolvida pelo Polo EaD que colabora para a iniciação do aluno na metodologia EaD aplicada pela IES e consequente para que alcance um melhor desempenho e aprendizado. A análise das respostas mostrou que os estudantes reconhecem a importância das atividades presenciais $e$ desejam que haja outras, além das obrigatórias, durante o desenvolvimento dos seus cursos. Para a IES e seus polos EAD, a realização sistêmica dessas atividades educacionais pode ser considerada como uma ação diferenciada que colabora para a permanência do seu aluno e ampliação da qualidade de sua formação acadêmica.
\end{abstract}

Palavras-chave: ATIVIDADES PRESENCIAIS EM POLOS EAD, ATIVIDADES PRESENCIAIS PARA CURSOS DE GRADUAÇÃO EAD, AULA INAUGURAL EM POLOS EAD, AULA INAUGURAL PARA CURSOS DE GRADUAÇÃO EAD, POLOS EAD. 


\section{INTRODUÇÃO}

A educação a distância - EaD, tem crescido de forma exponencial em todo o mundo. No Brasil, havia, em 2004, cerca de 60.000 alunos matriculados em cursos de graduação e em 2016, alcançou a marca de 1,5 milhão de matriculas, segundo levantamento realizado pelo Censo da Educação Superior (2016), oferecendo assim importante contribuição para a expansão da oferta da educação superior no país. Desde sua normatização por meio da LBD Lei № 9.394/96, até os dias atuais com o Decreto oㅜ 9.057/2017 e Portaria $n^{0}$ 11/2017, essa modalidade se propõe a democratizar o acesso ao ensino superior, por meio de Polos EaD, distribuídos em várias regiões do país com a vantagem de poder alcançar localidades em que uma Instituição de Ensino Superior IES, presencial, não chegaria devido ao elevado investimento necessário. O Polo EaD pode ser considerado um prolongamento da Instituição a qual está vinculado que além de prestar atendimento administrativo, atua como um facilitador na comunicação entre IES e discentes e também é lócus de ação para a formação acadêmica dos estudantes, na medida em que viabiliza a ampliação dos conhecimentos e da aprendizagem, por meio de atividades presenciais previstas nos Projetos Pedagógicos dos Cursos (PPCs). O trabalho apresentado tem como objetivo analisar a relevância das atividades presenciais promovidas pelos Polos EaD de uma Universidade Privada, na visão dos alunos, a partir das respostas registradas no relatório de Avaliação Institucional Interna, para um questionário aplicado em outubro de 2016 para 13.891 alunos matriculados e que obteve 6.531 respondentes em 05 polos-sede distintos. A análise da pesquisa se concentrou na Aula Inaugural, atividade presencial de suma importância para a integração e acolhimento do aluno na IES que escolheu estudar, além de promover uma adaptação mais rápida à metodologia $\mathrm{EaD}$ o que colabora para consolidar seu aprendizado e sua permanência no curso.

\section{REFERÊNCIAL TEÓRICO}

Desde a promulgação da Lei de Diretrizes e Bases da Educação (LDB), Lei n. 99.394 de 20 de dezembro de 1996, várias alterações foram realizadas nas diretrizes de regulação da Educação a Distância no Brasil, em relação aos cursos de Educação Superior. Em 2017. com a publicação do Decreto n. 9 9.057/2017, Portaria Normativa n. ${ }^{11 / 2017}$ e Decreto no 9.235/17, a ação regulatória torna-se mais aberta, permitindo que novos polos fossem cadastrados diretamente pelas Instituições de Ensino Superior - IES, devidamente credenciadas pelo MEC para a oferta de cursos, na modalidade a distância, sem a exigência de visita e aprovação prévia de avaliadores do MEC para o funcionamento dos Polos. A Portaria Normativa $n .{ }^{\circ}$ 11, de 20 de junho de 2017 altera 0 conceito de Polo no que se refere as regulamentações anteriores, substituindo o termo 
Polo de Apoio Presencial para Polo EaD e o considera como uma unidade acadêmica.

Art. 10. O polo de EaD é a unidade acadêmica e operacional descentralizada, no país ou no exterior, para o desenvolvimento de atividades presenciais relativas aos cursos superiores a distância.

Parágrafo único. É vedada a oferta de cursos superiores presenciais em instalações de polo EaD que não sejam unidades acadêmicas presenciais devidamente credenciadas (BRASIL, 2017b).

Para a Organização das Nações Unidas para Educação, Ciência e Cultura (UNESCO), a educação a Educação a Distância (EaD) consiste:

[...] no uso de técnicas, de recursos e de meios instrutivos específicos para facilitar a aprendizagem e o ensino entre alunos e professores que estão separados por tempo ou espaço. As técnicas, os recursos e os meios são dependentes de fatores como: conteúdo, necessidades e contexto do estudante, habilidades e experiência do professor, objetivos, tecnologias disponíveis e capacidade institucional (UNESCO, 2013).

$\mathrm{Na}$ interpretação desse princípio apresentado pela UNESCO, pode-se considerar que a IES credenciada na modalidade a distância, deve ter recursos e competências suficientes para viabilizar a Gestão Administrativa e Acadêmica, autoavaliação, experiência em EaD, equipe qualificada, professores e tutores titulados, instalações administrativas, serviços, recursos tecnológicos e biblioteca. Um dos itens abordados nos Referenciais de Qualidade para a Educação Superior a Distância no Brasil, documento elaborado pela Secretaria de Educação a Distância do MEC (SEED/MEC), é que o Polo EaD deve promover atividades presenciais, de modo a auxiliar a vida acadêmica do aluno, possibilitando novos conhecimentos. Nesse documento, que não tem força de Lei, mas é considerado pelo MEC um direcionador em suas avaliações institucionais e de cursos de graduação, destaca-se também a importância do Coordenador de Polos EaD, como o principal responsável pelo bom funcionamento dos processos administrativos e pedagógicos que se desenvolvem nessa unidade acadêmica, tendo conhecimento dos projetos pedagógicos dos cursos oferecidos no Polo, atentando-se para datas previstas no calendário acadêmico e zelando para que a infraestrutura esteja adequada para utilização dos discentes e viabilização das atividades (BRASIL, 2007).

Corroborando com a visão do Ministério da Educação e Cultura - MEC, para Weidle et al. (2011) os Polos EaD:

[...] são essenciais para o desenvolvimento dos cursos a distância, pois se constitui no local onde o aluno tem o apoio presencial, fornecido pela estrutura disponível - laboratórios de informática, salas de aula e biblioteca assim como os coordenadores e tutores presenciais, que incentivam e também auxiliam nas dúvidas dos alunos (WEIDLE et al. 2011, p.94) 
Ao se tratar do apoio dos tutores e colaboradores, enquanto os funcionários técnicoadministrativos do polo se encarregam pelo atendimento presencial e procedimentos administrativos, a tutoria responsabiliza-se pelo atendimento didático-pedagógico. Os tutores à distância, por estarem mais próximos aos professores, auxiliam com as dúvidas de conteúdo e acompanham o desenvolvimento das atividades, bem como as suas correções (UAB, 2011).

Como já apontado, este estudo se concentrou na Aula Inaugural, atividade presencial, não obrigatória, de suma importância para a integração e acolhimento do aluno ingressante na IES que escolheu estudar, além de promover uma adaptação mais rápida à metodologia $\mathrm{EaD}$ o que colabora para sua permanência no curso. De acordo com Machado e Lopes (2011, p. 6), a aula inaugural é realizada pelo Polo EaD, "visando acolher novos alunos e orientá-los nessa jornada acadêmica que estão iniciando". Os autores destacam a importância de motivar os alunos para a nova fase que estão iniciando e também a orientação sobre o curso, organização dos módulos e disciplinas, manual do aluno, avaliações e etc.

Ainda para Machado e Lopes :

Uma das partes mais importantes da aula inaugural é a orientação sobre o acesso ao Sistema Único de Aprendizagem. Para tal utiliza-se um computador conectado à internet e é simulado um acesso mostrando todos os links do sistema explicando como o aluno deve acessá-Io. (MACHADO e LOPES, $(2011$, p. 6).

Além da aula inaugural, o polo pode oferecer aos alunos palestras, workshops, oficinas, atividades presenciais em grupo, de modo que possam contribuir com o aprendizado dos alunos. De acordo com o objetivo proposto neste trabalho, a partir da análise dos dados, busca-se refletir se para os alunos participantes da pesquisa realizada pela CPA as atividades presenciais possuem relevância para a sua formação acadêmica.

\section{METODOLOGIA}

A luz do propósito exposto acima, a pesquisa será de natureza qualitativa e quantitativa com características exploratórias, por meio de coleta de dados. Será fundamentada a partir da revisão de literatura, que contou com o apoio de autores que discutem sobre educação a distância. Também foi necessária uma análise documental do Relatório de Avaliação Institucional Interna, elaborado pela Comissão Própria de Avaliação (CPA) da Instituição de Educação Superior estudada, uma vez que os dados da pesquisa foram levantados a partir do relatório de Avaliação Institucional Interna, a fim de se compreender qual a importância das atividades presenciais promovidas pelos Polos EaD na visão dos alunos. O questionário foi aplicado aos alunos em outubro de 2016, para 
13.891 alunos matriculados, em 05 polos distintos, obteve 6.531 respondentes. Em relação ao questionário aplicado como instrumento de coleta de dados, a CPA utilizou para a avaliação institucional interna, 02 (duas) propostas avaliativas: a primeira, com abordagem quantitativa, por meio de instrumentos próprios avaliativos, onde foram elaboradas 47 (quarenta e sete) questões de múltipla escolha, as quais contemplam Dimensões / Eixos que estão previstos no SINAES, conforme a seguir: 13 (treze) questões para identificar o perfil socioeconômico dos alunos, 10 (dez) questões para analisar o atendimento do Polo EaD, 10 (dez) questões sobre as atividades acadêmicas nos Polos e por fim, 14 (quatorze) questões sobre a infraestrutura do Polo; a segunda com abordagem qualitativa, pois a partir de questões abertas, o aluno faz a colocação que desejar e, posteriormente, tais colocações são subdivididas em categorias. Este estudo se limitará à análise das respostas dos alunos acerca de 3 (três) questões a respeito das atividades presenciais realizadas no Polo e as manifestações em relação a este tema na questão aberta.

\section{Análise dos dados}

Para fins da realização da pesquisa proposta, foram selecionados os 03 gráficos que tratam no instrumento de coleta de dados aplicado, sobre questões relacionadas às atividades presenciais promovidas pelos Polos EaD estudados. Para análise dos resultados, foi considerada uma média simples dos resultados de cada polo, indicando como satisfação dos respondentes os percentuais obtidos nos itens: Concordo Plenamente, Concordo e Tendo a Concordar e foi considerado insatisfação, os percentuais relacionados aos itens: Tendo a Discordar, Discordo e Discordo Totalmente. O item não se aplica, foi interpretado como sem resposta, de forma que o aluno não soube responder.

Para a questão que indagava sobre a realização pelo polo EaD de atividades extracurriculares (palestras, oficinas ou aulas de reforço), observa-se no gráfico 1 , que a média de satisfação dos alunos respondentes é de $62 \%$, e insatisfação $30 \%$. Os alunos que preferiram não se manisfestar, ou não souberam responder, resultou a média de cerca de $8 \%$.

Gráfico 1 - O polo promove atividades presenciais extra -curriculares (palestras, oficinas ou aulas de reforço) 


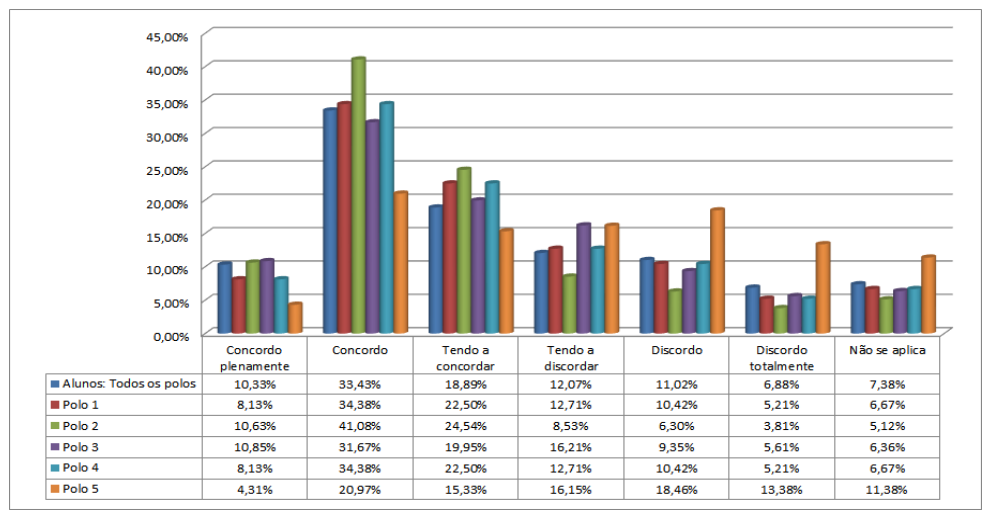

Fonte: Relatório de Avaliação Institucional Interna (2016). Adaptado pelos autores

No que se refere as respostas qualitativas, encontrou-se em relação a este tema os seguintes argumentos dos alunos:

Quadro 1- Síntese das respostas qualitativas para questão aberta sobre realização pelo Polo EAD de atividades extra-curriculares (palestras, oficinas ou aulas de reforço)

\begin{tabular}{|l|}
\hline "Precisamos de mais atividades presenciais no polo" \\
\hline "O polo deve apresentar mais assistência ao aluno, ter mais palestras, mais \\
atividades oferecidas no polo". \\
\hline \begin{tabular}{l} 
"Quanto as atividades acadêmicas, no meu ponto de vista falta palestras sobre o \\
curso, atividades onde os alunos pudessem ter mais contatos com os professores no \\
ambiente acadêmico". \\
\hline "Gostaria que houvesse atividades complementar em outro dia que seja sexta a noite \\
nem sábado em outro dia a noite". \\
"Sou aluna do curso de [..], e gostaria de solicitar que o Polo oferecesse atividades \\
presenciais voltadas a esse curso, como palestras, oficias ou cursos e que indicasse \\
palestras e atividades que possam importantes para nós estudantes"
\end{tabular} \\
\hline
\end{tabular}

Considerando que dos 6531 respondentes cerca de $30 \%$ dos alunos estão insatisfeitos com as atividades presenciais oferecidas pelos Polos EaD estudados, é importante que a Universidade objeto da pesquisa realize um replanejamento de atividades presenciais, com o apoio das Coordenações de Curso e de Polos EaD, com o intuito de aproximar o aluno do Polo, fomentar novos conhecimentos e contribuir com a formação acadêmica dos discentes.

O Polo 5 obteve o maior índice de insatisfação (quase 50\%) em relação as atividades extra-curriculares. Dentre os demais, este polo é o que mais necessita de atividades desta natureza para os alunos.

O gráfico 2 expressa as respostas dos alunos respondentes em relação a questão se o Polo EaD convidou o aluno a participar da aula inaugural no início do curso. 


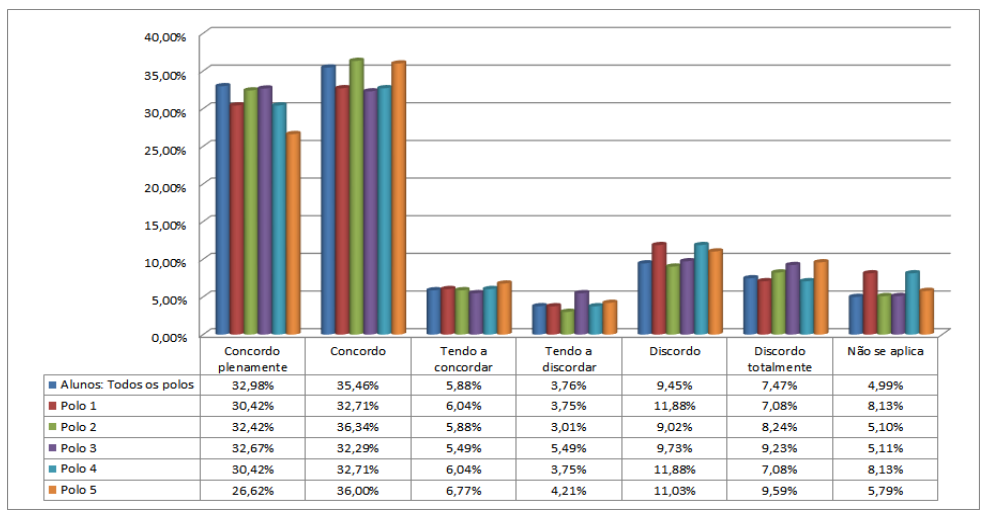

Fonte: Relatório de Avaliação Institucional Interna (2016). Adaptado pelos autores

Ao analisar a média de respostas, observa-se que em média $74 \%$ dos alunos afirmam que foram convidados para a aula inaugural no início do curso, $21 \%$ não concordam ou não foram convidados e 5\% não souberam responder.

Em relação as respostas qualitativas, encontrou-se os seguintes argumentos negativos dos alunos respondentes da pesquisa:

Quadro 2- Síntese das respostas qualitativas para questão aberta sobre realização pelo Polo EAD de convite para participação na aula inaugural, no início do curso.

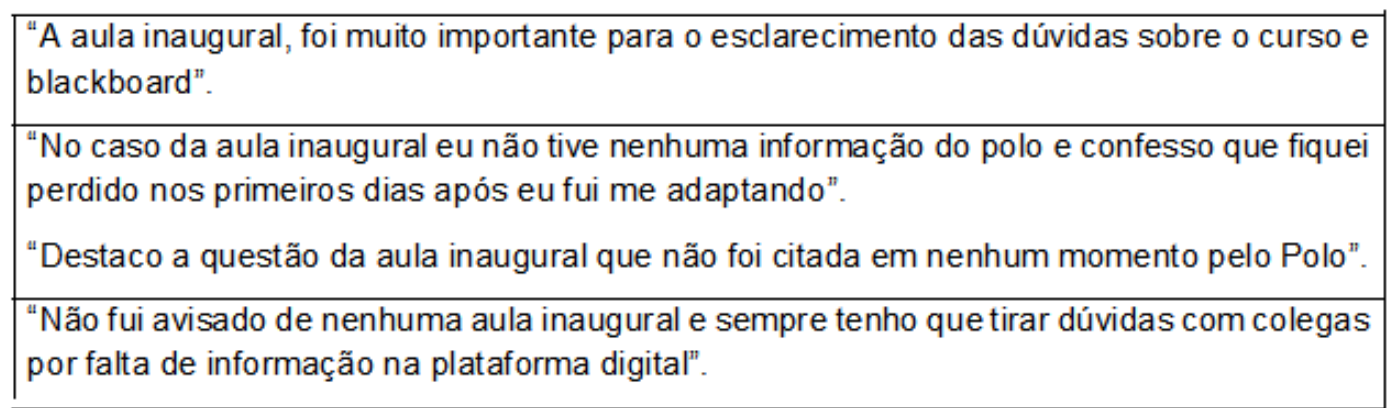

Dos 6531 alunos participantes da pesquisa quantitativa, 4833 respondentes afirimaram que foram informados a respeito da aula inaugural pelo Polo, mas 1331 alunos, o que representa cerca de $17 \%$ dos respondentes, escolheram alternativas de respostas que indicam que não foram devidamente comunicados. A aula inaugural, como já explanado neste estudo, tem papel fundamental para auxiliar o aluno no início do curso. É o momento de aproximação do aluno com o Polo EaD, o qual irá apresentar e detalhar os procedimentos da Universidade, infraestrutura disponível e acesso ao ambiente virtual de aprendizagem. Desse modo, considerando sua importância para permanência do aluno no Curso, pode-se inferir que a Universidade estudada precisa aprimorar sua comunicação com os alunos matriculados por polo, para que todos tenham a ciência da importância da aula inaugural, bem como dias e horários de oferta. 
O gráfico 3 é o resultado do questionamento aos alunos participantes da pesquisa sobre as informações apresentadas na aula inaugural para saber se elas auxiliaram a compreender o funcionamento da educação a distância. Analisando a média geral, 62\% dos alunos concordam que a aula inagural auxiliou a compreender a EaD, 13\% não concordam e cerca de $25 \%$ preferiram não opinar ou não souberam responder.

Gráfico 3 - As informações apresentadas na aula inaugural me auxiliaram a compreender o funcionamento da educação a distância.

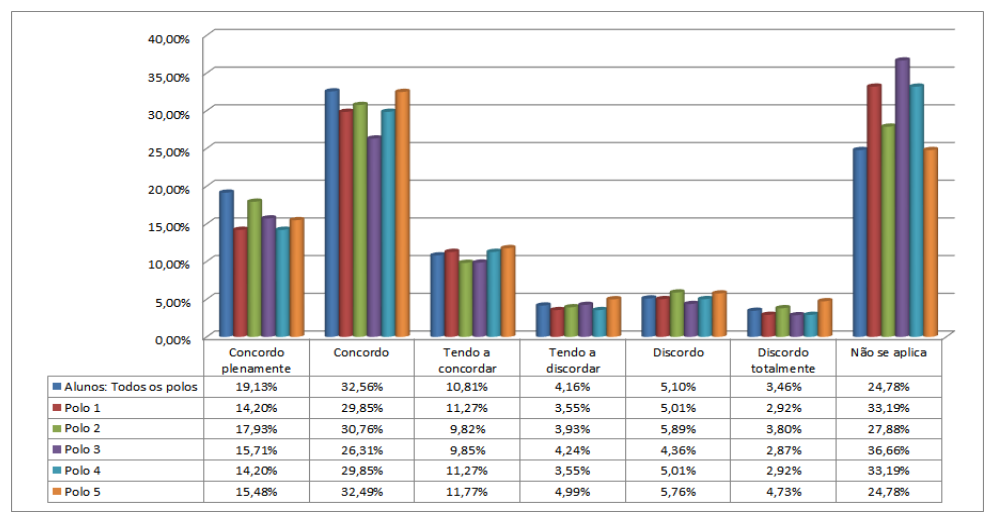

Fonte: Relatório de Avaliação Institucional Interna. Adaptado pelos autores

A respeito das respostas qualitativas, encontrou-se os seguintes argumentos dos alunos respondentes da pesquisa:

Quadro 3- Síntese das respostas qualitativas para questão aberta sobre se as informações apresentadas na aula inaugural auxiliaram 0 aluno a compreender 0 funcionamento da educação a distância.

"Comecei a estudar neste semestre e não fui informado sobre aula inaugural, nem pelo site da faculdade e nem no polo nas várias vezes em que estive por lá tentando esclarecer minhas dúvidas".

"Não fiz a aula inaugural porque os materiais de explicação de uso do blackboard foi completo". "Sobre a aula inaugural, não tive nenhum aviso então o pouco que eu sei do sistema aprendi sozinha".

"Vejo muita gente que não participou da aula inaugural e tem dúvidas de tudo".

Ao analisar que, dos 6351 alunos respondentes cerca de 25\% deles, ou mais objetivamente, 1632 não souberam responder se as informações da aula inaugural auxiliaram a compreender o funcionamento da EaD, percebeu-se que os estudantes não participaram da atividade ou não compreenderem o que ela representava, por falta de orientação e convite do Polo ou ainda por decisão própria do aluno de não participar. $O$ aluno que não realiza a aula inaugural, não compreende os procedimentos da Universidade, metodologia de ensino aplicada, critérios de avaliação, serviços disponíveis, estágios, atividades complementares e outras informações relevantes, 
defrontando-se com dificuldades no cotidiano dos seus estudos, no manuseio do ambiente virtual e informações sobre seu curso, polo e instituição. A falta de articipação em uma atividade tão importante poderia prejudicar o aluno na realização das atividades que terá de fazer durante o curso, pelo fato de não ter conhecimentos básicos que poderiam fornecer informações importantes para seu desenvolvimento durante o curso.

\section{CONSIDERAÇÕES FINAIS}

As diretrizes estabelecidas pelo MEC, por meio do atual Marco Regulatório da Educação a Distância, evidenciam a importância dos Polos EAD no processo de ensino e aprendizagem do aluno bem como para a sua inclusão e permanência em cursos de graduação, oferecidos na modalidade a distância. A pesquisa apresentada, buscou analisar a relevância da realização de atividades presenciais previstas e alinhadas com Projetos Pedagógicos dos Cursos oferecidos, em especial da atividade AULA INAUGURAL, para promover uma maior adaptação do aluno e sua permanência no curso. A análise dos resultados apresentados na pesquisa em tela, demonstram que 0 aluno reconhece $\mathrm{o}$ valor das atividades presenciais e indica que gostaria houvesse em maior número, variedade e alinhadas ao seu curso. Evidencia-se também a necessidade da IES e seus polos que foram avaliados nesse estudo, rever e replanejar suas ações de forma a minimizar ou eliminar as fragilidades identificadas no processo de avaliação de forma a alcançar maior participação dos alunos nas atividades presenciais, reduzindo a possibilidade de sua evasão ou aprendizado limitado durante a realização do curso escolhido. Para a IES e seus polos EaD, a realização sistémica dessas atividades educacionais pode ser considerada como uma ação diferenciada que colabora para a permanência do aluno e ampliação da qualidade em sua formação acadêmica. Embora os referencias de qualidade não tenham força de lei, é considerado um direcionador que auxilia os atos legais do poder público no que se refere aos processos específicos de regulação, supervisão, avaliação e monitoramento da modalidade a distância. Como um direcionador para a IES destaca-se a importância da aula inaugural para os ingressantes na modalidade EaD, como um momento de acolhimento, de recepção e orientações aos discentes sobre o curso, sobre os serviços disponíveis, sobre a biblioteca, e o ambiente virtual de aprendizagem, local de suas interações com o conteúdo, tutores, professores e avaliações.

\section{REFERÊNCIAS}

BRASIL.MEC. Lei n. 9.394, de 20 de dezembro de 1996. Diário Oficial da União, Brasília, DF, 1996. 
. Referenciais de qualidade para educação superior a distância. Brasília, Agosto de 2007.

Portaria n. 11, de 20 de junho de 2017, DOU 21 de junho de 2017.

CRESWELL, J. W. Projeto de pesquisa: Métodos qualitativo, quantitativo e misto, $3^{\text {a }}$ ed. Porto Alegre, Artmed, 2010.

GIL, A. C. Como elaborar projetos de pesquisa. 4. ed. São Paulo: Atlas, 2002.

INEP/MEC. Instituto Nacional de Estudos e Pesquisas Educacionais Anísio Teixeira. Censo da educação superior 2016. Brasília, DF, 2016.

LANDIM, Claudia Maria Ferreira. Educação à distância: algumas considerações. Rio de Janeiro, 1997.

MACHADO, Diane Cristina de Almeida; LOPES, Luis Fernando. A importância de práticas tutorias nos cursos superiores na modalidade a distância. $X$ Congresso Nacional de Educação. PUC, Paraná, 2011. Disponível em: . Acesso em 14 abr 2018.

MOORE, M. G; KEARSLEY, G. Educação à distância: uma visão integrada. São Paulo: Thomson Learning, 2007.

PORTAL UAB. Disponível em: . Acesso em: 01 out 2017.

PRODANOV, Cleber Cristiano; FREITAS, Ernani Cesar de. Metodologia do Trabalho Cientifíco: Métodos e Técnicas da Pesquisa e do Trabalho Acadêmico, 2º Edição.Novo Hamburgo: Feevale, 2013.

UNESCO. CONSELHO NACIONAL DE EDUCAÇÃO. Desenvolvimento, aprimoramento e consolidação de uma educação nacional de qualidade. 2013. Relatório.

WEIDLE, Daniele; KICH, Juliane Ines Di Francesco; PEREIRA, Mauricio Fernandes. Projeto UAB: uma análise estrutural dos pólos de apoio presencial do curso de Administração da UFSC. Revista Gestão Universitária na América Latina - GUAL, Florianópolis, p. 94-114, jan. 2011. ISSN 1983-4535. Disponível em. Acesso em: 02 mar. 2018. 